\title{
O ESPORTE É UMA PRÁTICA DE BEM-ESTAR ILUSÓRIO NO SUJEITO?
}

\author{
IS THE SPORT AN ILLUSORY WELLFARE
}

ON THE SUBJECT?

\begin{abstract}
AUTOR
Rogério Rodrigues'

${ }^{1}$ Universidade Federal de Itajubá

O ESPORTE É UMA

PRÁTICA DE BEM-ESTAR

ILUSÓRIO NO SUJEITO?

4(2): $85-87$

\section{PALAVRAS-CHAVE}

educação física; educação do corpo; educação; filosofia.

\section{KEYWORDS}

physical education; education of the body; education; philosophy.
\end{abstract}

\section{RESUMO}

Partimos da tese de que o "bem-estar" do sujeito no esporte é analisado pela área da Educação Física como aquilo que promove a condição de saúde física e proporciona o equilíbrio emocional. Esta análise está centrada na premissa de que no campo das ciências biológicas e psicológicas as práticas esportivas proporcionam resultados benéficos ao sujeito, ou seja, "esporte é saúde". Entretanto, da leitura do texto de Freud intitulado o "Mal-estar na Civilização" propomos analisar outras relações que os sujeitos podem estabelecer com o esporte. Neste caso, compreendemos o esporte para o sujeito a considerando dois enfoques, ou seja, como um método substitutivo ou uma sublimação para o homem encontrar a satisfação de seus "impulsos". Entretanto, colocamos em dúvida se seria possível a realização de uma prática esportiva que permitisse ao sujeito uma relação objetal na qual este possa encontrar a plena satisfação de suas "pulsões".

\section{ABSTRACT}

We start from the theory of that the "welfare" of the subject in the sport is analyzed by the area of the Physical Education as what promotes the condition of physical health and provides the emotional equilibrium. This analysis is centered on the premise that in the field of the biological and psychological sciences, the sporting practices provides beneficial results to the individual, that is, "sport is health". However, of the reading of the Freud text titled the "Civilization and Its Discontents" we are going to analyze other relations that the subjects can establish with the sport. In that case, we understand the sport for the subject, considering two approaches, that is, as a substituting approach or sublimation for the man to find the satisfaction of his "impulses". We put in doubt would be been possible the achievement of a sporting practice that permitted to the subject a objetal relation in which he can find to full satisfaction of his "impulses". 


\section{INTRODUĈ̣̃O}

Em nossa sociedade moderna é senso comum que a prática do esporte é sinônimo de saúde física e que também proporciona um certo equilíbrio emocional ao sujeito. Não precisamos procurar muito entre os esportistas para afirmarmos essa tese de que "esporte é saúde", pois logo, em qualquer academia de ginástica, podemos encontrar os diversos cultuadores do corpo. Estes são detentores de discursos sobre os "cuidados de si" e determinam como regra de que devemos realizar no uso "técnico do corpo" o sentido de nos mantermos sempre saudáveis e, principalmente, felizes. Basicamente, podemos dizer que estes buscam nestas práticas corporais esportivizadas encontrar a felicidade perdida em suas relações sócias. Contudo, não podemos nos esquecer que para Freud:

Nossas possibilidades de felicidade sempre são restringidas por nossa própria constituição. Já a infelicidade é muito menos difícil de experimentar. 0 sofrimento nos ameaça a partir de três direções: de nosso próprio corpo, condenado à decadência e à dissolução, e que nem mesmo pode dispensar o sofrimento e a ansiedade como sinais de advertência; do mundo externo, que pode voltar-se contra nós com forças de destruição esmagadoras e impiedosas; e, finalmente, de nossos relacionamentos com os outros homens. ${ }^{1}$
Neste caso, o que podemos dizer dos cultuadores das práticas corporais esportivizadas que buscam através do uso "técnico do corpo", como uma formação reativa, evitar o "mal-estar" provenientes das nossas relações sócias? Diríamos que estes partem de pressuposto ilusório, qual seja, da possibilidade de controlar as relações entre o seu "eu" e o próprio corpo e mantendo este último como uma eterna fonte de prazer. Entretanto, existiria uma verdade constituída para sermos sempre saudáveis e felizes?

Paradoxalmente, podemos observar no campo da Educação Física e Esporte a existência de um certo número de sujeitos que ditam as regras de que devemos proceder obstinadamente no sentido de fazermos esporte todos os dias. Contudo, são estes mesmos, em sua grande maioria, que não praticam nenhum tipo de atividade física. Neste caso, podemos aqui sinalizar que nesses discursos para o exercício das práticas corporais esportivizadas, mais propriamente, nas relações entre teoria e prática, há certa falta de sentido, pois se falamos que devemos ter práticas esportivas (teoria) e não temos (prática) produzimos um rompimento com a verdade. Neste caso, ocorre uma situação em que não se coaduna o objeto da abstração e a realização da prática.

Qual seria o ponto central para analisarmos esta falta de coadunação entre teoria e prática no que diz respeito aos cuidados do corpo no campo das práticas esportivas?
Consideramos que esse ponto central refere-se à tese de que se tivéssemos que proclamar uma meta para a vida, diríamos que todos nos esforçamos para obter a felicidade e assim queremos permanecer. Neste sentido, compreendemos que através do uso do corpo busca-se encontrar a saúde e a felicidade e, para tanto, não medimos esforços. Entretanto, muitas vezes nos arriscamos a diversas práticas sem levar em conta de que estas nos trazem um sentimento de que o corpo é totalmente oposto à idéia de uma fonte de prazer.

Para quem prática esporte isso não é nenhum tipo de novidade, ou seja, de que as rotinas e os esforcos desprendidos nos treinos não proporcionam grau algum de felicidade. Não podemos nos esquecer que muitas vezes os esforços dos treinos acabam por resultar em lesões no uso do corpo que podem colocar em risco todo os preparativos de meses e às vezes de anos. Neste caso, questiona-se: como podemos considerar a prática do esporte como uma fonte de promoção de "bem-estar" no sujeito? Não estaríamos centrando nossas atividades corporais esportivizadas em práticas de bem-estar ilusórias no sujeito?

Ao colocarmos em dúvida essa promessa de felicidade e saúde estamos de certo modo destituindo a crença na tese do "bem-estar" no sujeito que prática o esporte. Pensamos que instituir essa "crise" é proporcionar as condições de que a premissa de saúde e felicidade 
discursada pela área da Educação Física e Esporte perca a condição de "ilusão" e se materialize em práticas centradas na verdade do sujeito. Entretanto, o que seria a "verdade do sujeito"?

É necessário ter mais cautela na aceitação da tese biológica de que a prática esportiva proporciona resultados benéficos ao sujeito, ou seja, "esporte é saúde". Neste caso, o que se poderia dizer das diversas lesões e os danos a saúde que resultam da prática sistemática do esporte?

0 sujeito lesionado defronta-se com a condição de que a prática do esporte produz resultados que não necessariamente sejam centrados na saúde. Naquilo que corresponde ao que denominamos de equilíbrio emocional o que se pode dizer das alterações de humor e a expansão da violência na prática do esporte? Ainda mais, o que se pode dizer sobre os motivos que levam aos "profetas da felicidade e saúde" - os profissionais da Educação Física a não praticarem esporte, pois é muito comum, entre esses profissionais a total abstinência de práticas esportivas e isso por si só seria um fato para questionarmos sobre a validade da tese de que a prática do esporte é salutar ao sujeito. A prática do esporte em muitos casos exige muita disciplina e submissão e nem todos estão preparados para esse tipo de exigência. Se isto é uma verdade como podemos justificar o fascínio e distanciamento ou amor e ódio que os sujeitos estabelecem em relação às práticas esportivas?
Diríamos que temos um ponto para se pensar e isso seria o fato de ser imprescindivel a análise da adesão da prática esportiva em outros significados que não sejam balizados pelo discurso da saúde e nem o do equilíbrio emocional.

Compreendemos que na prática do esporte existe presente algo que permite ao sujeito estabelecer uma relação duradoura e uma fixação em seu exercício corporal. A partir do texto de Freud intitulado o "Mal-estar na Civilização" propomos a analisar essas outras relações que fixam os sujeitos na escolha de determinadas práticas de esportes. Desde já podemos assumir a hipótese de que cada tipo de sujeito, mais propriamente, cada tipo de "neuroses" tende a se aproximar de práticas esportivas que lhe proporcionam uma certa similitude com os seus sintomas. Isso por si só já seria um tipo de escolha das relações entre o sujeito e a prática do esporte. Neste caso, podemos compreender as relações do sujeito com o esporte considerando de dois enfoques, ou seja, como um modo facilitador, mais propriamente, um método substitutivo ou uma sublimação para o homem encontrar a satisfação de seus "impulsos". Entretanto, seria mesmo a prática do esporte uma relação objetal na qual o sujeito possa encontrar a plena satisfação das "pulsões"? Seria mais apropriado questionarmos sobre essa possibilidade, uma vez que nestas relações pode-se viver a derrota, mais propriamente, a frustração, o que proporciona um sentimento inverso, ou seja, um sentimento de sofrimento. Neste paradoxo, a frustração não permite compreender o fascínio do sujeito pelo esporte, pois o sofrimento perante a derrota deveria afastá-lo desse objeto. Contudo, o sujeito encontra-se envolvido cada vez mais comprometido com a prática do esporte, mesmo que esta traga sofrimento e perda. Neste aspecto, temos que analisar a relação do sujeito com o esporte como algo que se encontra "para além do princípio de prazer"2, mas isso será assunto para uma outra discussão.

\section{CORRESPONDÊNCIA}

Rogério Rodrigues

Rua Corinto, 543 ap. 126 bloco C

Butantã - São Paulo - S. P.

Cep. 05586 - 060

Brasil

\section{REFERÊNCIAS}

1. Freud Sigmund (1990). O Mal-Estar na Civilização (1930 [1929]). In: ___. Obras Completas. v. XXI. Trad. Jayme Salomão. Rio de Janeiro: Imago, 85 (grifo nosso).

2. Cf. Freud Sigmund (1990). Além do princípio de prazer (1920). In: Obras Completas. v. XVIII. Trad. Jayme Salomão. Rio de Janeiro: Imago. 